\title{
Effect of physical and sexual violence during childhood and/or adolescence on the development of menstrual related mood disorders: A systematic review and meta-analysis
}

\author{
Dannia Islas-Preciado, 'Karla Flores-Celis, ${ }^{2}$ Jorge González-Olvera, ${ }^{3}$ Erika Estrada-Camarena
}

Laboratorio de Neuropsicofarmacología, Dirección de Neurociencias, Instituto Nacional de Psiquiatría Ramón de la Fuente Muñiz (INPRFM), Ciudad de México, México.

2 Dirección de Investigaciones Epidemiológicas y Psicosociales, INPRFM, Ciudad de México, México.

3 Dirección de Investigaciones Clínicas, INPRFM, Ciudad de México, México.

\section{Correspondence:}

Erika Estrada-Camarena

Laboratorio de Neuropsicofarmaco-

logía, Dirección de Neurociencias, INPRFM

Calz. México-Xochimilco 101,

San Lorenzo Huipulco,

Tlalpan, 14370, Ciudad de México, México.

Phone: $554160-5053$

Email: estrada@imp.edu.mx

Received: 17 April 2019

Accepted: 19 March 2020

Citation:

Islas-Preciado, D., Flores-Celis, K. González-Olvera, J., \& Estrada-Camarena, E. (2021). Effect of physical and sexual violence during childhood and/or adolescence on the development of menstrual related mood disorders: A systematic review and meta-analysis. Salud Mental, 44(3), 145-153.

DOI: $10.17711 /$ SM.0185-3325.2021.019

\begin{abstract}
Background. Abuse in early life stages has been proposed as an etiological risk factor for developing menstrually-related mood disorders (MRMDs). Objetive. To evaluate whether there is a relation between the occurrence of physical and/or sexual violence in childhood and/or adolescence and the development of MRMDs in adulthood. Method. A systematic search was conducted in PubMed, Web of Science, and ScienceDirect, with the route ("Premenstrual Syndrome"[Mesh]) OR ("Premenstrual Dysphoric Disorder"[MeSH]) AND ("Violence"[Mesh]) / ("menstrually-related mood disorders" AND "abuse"). Fifty-four articles were initially reviewed and 32 were excluded based on the criteria. Twenty-two articles were thoroughly reviewed. Finally, five articles (publication years 2014, 2013, 2012, 2007, and 2003) were included in the systematic review and submitted to a meta-analysis. Results. Results indicate that having been exposed to physical and/or sexual violence in childhood and/or adolescence increases 1.99 times the risk of experiencing MRMDs in adulthood in comparison with women who did not experience that type of violence (odds ratio [OR] = 1.99; 95\% confidence interval [1.58, 2.51]). Discussion and conclusion. The present work provides evidence that a woman who experienced violence through physical and/or sexual abuse during childhood and/or adolescence has a greater risk of developing MRMDs in adulthood.
\end{abstract}

Keywords: Violence, sexual abuse, physical abuse, menstrually-related mood disorders.

\section{RESUMEN}

Antecedentes. El abuso en las etapas tempranas de la vida se ha propuesto como un factor de riesgo etiológico para desarrollar trastornos del estado de ánimo relacionados con la menstruación (TEARM). Objetivo. Evaluar si existe una relación entre la ocurrencia de violencia física y/o sexual en la infancia y/o la adolescencia y el desarrollo de MRMD en la edad adulta. Método. Se realizó una búsqueda sistemática en PubMed, Web of Science y ScienceDirect con la ruta ("Premenstrual Syndrome"[Mesh]) OR ("Premenstrual Dysphoric Disorder"[MeSH]) AND ("Violence"[Mesh]) / ("menstrually-related mood disorders" AND "abuse”). Cincuenta y cuatro artículos fueron revisados inicialmente y 32 fueron excluidos con base en los criterios establecidos. Veintidós artículos fueron revisados exhaustivamente. Por último, se incluyeron cinco artículos (años de publicación 2014, 2013, 2012, 2007 y 2003) en la revisión sistemática, y cinco de ellos fueron sometidos a un metaanálisis. Resultados. Los resultados indican que haber estado expuesta a violencia física y/o sexual en la niñez y/o la adolescencia aumenta 1.99 veces el riesgo de experimentar TEARM en la edad adulta en comparación con las mujeres que no experimentaron ese tipo de violencia (odds ratio $[\mathrm{OR}]=1.99$; intervalo de confianza del 95\% [1.58-2.51]). Discusión y conclusión. El presente trabajo aporta evidencia de que una mujer que experimentó violencia por abuso físico y/o sexual durante la niñez y/o la adolescencia tiene un mayor riesgo de desarrollar TEARM en la edad adulta.

Palabras clave: Violencia, abuso sexual, abuso físico, trastornos del estado de ánimo relacionados con la menstruación. 


\section{BACKGROUND}

It is estimates that roughly $75 \%$ of women in reproductive age report physical premenstrual changes, and an additional percentage is affected by menstrually-related mood disorders (MRMDs), a term that has been used to encompass both premenstrual syndrome (PMS) and premenstrual dysphoric disroder (PMDD) (Bunevicius, Leserman, \& Girdler, 2012; Crowley, Pedersen, Leserman, \& Girdler, 2015). PMS affects approximately $20 \%$ to $50 \%$ of women (APA, 2000; Pearlstein \& Steiner, 2012), and a smaller percentage (3\% to $8 \%$ ) meets criteria for PMDD (Yonkers, O’Brien, \& Eriksson, 2008), the severe form of PMS.

According to the Diagnostic and Statistical Manual of Mental Diseases-5 (DSM-5), PMDD is characterized by the presence of irritability, affective lability, anxiety, and depression, among others, in addition to physical symptoms (APA, 2013), that may impair social relations in family, school, and work environments (APA, 2000).

Premenstrual symptoms come about cyclically and their severity may vary over time, which difficult to accurately diagnose it and to study it systematically (APA, 2000). However, it is important to take into account the negative impact on the lives who experience MRMDs, and even more, the presence of these disorders increases the vulnerability of suffering post-partum depression (MacKenzie \& Maguire, 2014) and psychiatric disorders in the perimenopause period (Studd \& Nappi, 2012).

One etiological factor of MRMDs is the exposure to significant stressful events (Hantsoo \& Epperson, 2015), such as physical and sexual violence during childhood and adolescence (Golding, Taylor, Menard, \& King, 2000; Koci \& Strickland, 2007). Nonetheless, to our knowledge, this population does not have access to timely interventions to counteract the negative consequences that stressful experiences could bring. In this regard, it has been suggested that sexual abuse affects the functioning of the hypothalamus-pituitary-adrenal (HPA) axis (Schalinski, Elbert, Steudte-Schmiedgen, \& Kirschbaum, 2015; Trickett, Noll, Susman, Shenk, \& Putnam, 2010), which seems to be evident in women with MRMDs (Klatzkin, Morrow, Light, Pedersen, \& Girdler, 2006; Roca et al., 2003), leading to an impairment in the stress response and affecting adaptive processes (McEwen, 1998; McEwen, Eiland, Hunter, \& Miller, 2012). Although there is not a mechanism that fully explains how abuse contributes for developing MRMD, it has been showed that abused women have lower concentrations of noradrenaline, higher heart rate, increased $\beta$-adrenergic receptor response, and lower plasmatic cortisol at rest and during stress, suggesting that the response of HPA axis is blunted (Girdler et al., 2003; 2007). The authors suggested that this deregulation is a consequence of earlier and persistent traumatic experiences that impair the adaptive mechanism of stress regulation and increase the vulnerability of women to present MRMD (Girdler et al., 2007).

Alarmingly, girls are thrice more likely of being sexually abused than boys, and this probability is six times greater for female adolescents and young adults than women in other ages (Koci \& Strickland, 2007). Given the high prevalence of abuse among girls and female adolescents, it is feasible to hypothesize that MRMDs is misdiagnosed and, therefore, the prevalence could be higher than the observed previously (APA, 2000; Pearlstein \& Steiner, 2012; Yonkers et al., 2008). Hence, demonstrating an association between abuse and MRMDs may help foster timely interventions to decrease the risk of developing MRMDs in adulthood. Due to this, the present systematic review and meta-analysis aimed to evaluate in case-control studies whether there is a relation between physical and sexual violence in childhood and/or adolescence and the development of MRMDs in adulthood.

\section{METHOD}

\section{Design of the study}

We conducted a systematic search in Medline (PubMed), Web of Science, and ScienceDirect, with the search route ("Premenstrual Syndrome"[MeSH]) OR ("Premenstrual Dysphoric Disorder"[MeSH]) AND ("Violence"[MeSH]) / ("menstrually related mood disorders" AND "abuse"). Eighty-six articles were found and integrated into a single database. Articles that were repeated (32) or did not meet the selection criteria of case versus control with physical and/or sexual violence in adolescence and/or childhood as an independent variable were discarded, resulting in the inclusion of five articles. It is important to mention that search for "menstrually-related mood disorders" was explored directly in the PubMed searching box as a MeSH term and did not show results. However the term was used to encompass both premenstrual syndrome (PMS) and premenstrual dysphoric disroder (PMDD) (Bunevicius et al., 2012; Crowley et al., 2015). The present work was performed based on the Preferred Reporting Items for Systematic Reviews and Meta-Analyses guidelines (PRISMA) (Liberati et al., 2009).

\section{Procedure}

In the first filter, three reviewers examined the abstracts of 54 articles (Kappa Index, 70\%; $p<.05$ ) published between 1987 and 2018, this because the DSM-III-R added formal criteria to operationalized the diagnosis of premenstrual dysphoria in 1987 (Spitzer, Severino, Williams, \& Parry, 1989). The articles excluded were systematic reviews, articles involving other mental disorders diagnosed by structured clinical psychiatric interviews, qualitative or case studies, studies on psychological and/or psycho- 

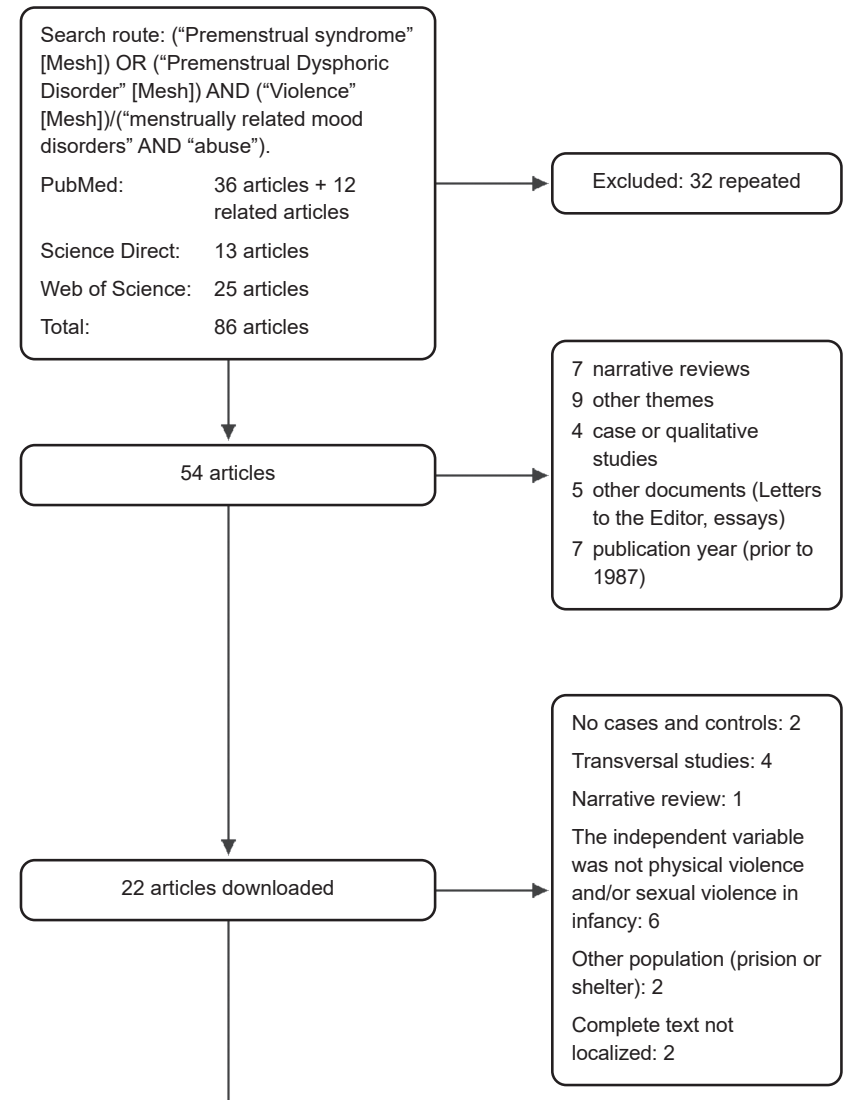

5 articles included: Bertone-Johnson et al., 2014; Bunevicius et al., 2012;

Fleischman et al., 2014; Girdler et al. 2007; Girdler et al., 2003.

Figure 1. Flowchart of the search for the systematic review.

analytical theories, and studies in other formats (letters to the editor, essays).

Subsequently, 22 articles were downloaded for a full examination made by two reviewers and discrepancies were solved by a third reviewer (Kappa index 70\%, $p<$ .05 ). Articles that did not meet the criteria of case-control studies with physical and/or sexual violence in adolescence and/or childhood as an independent variable were discarded. Therefore, the following were excluded: Bunevicius et al. (2013), Crowley et al. (2015), Girdler et al. (1998) and Girdler et al. (2004); Soyda Akyol, Karakaya Arısoy, and Çayköylü (2013), Wittchen, Perkonigg, and Pfister (2003). As well, were excluded cross-sectional studies (Golding et al., 2000; Koci \& Strickland, 2007; Kovac, Klapow, Kroenke, Spitzer, \& Williams, 2003; Segebladh et al., 2011), and narrative reviews (Ross \& Steiner, 2003). Also, those studies conducted in prisons or shelters (Ersoy \& Yildiz, 2011; Sousa-Rodrigues et al., 2006), and articles which complete text could not be obtained despite the efforts to contact the original authors (Howard, Mason, \& Ebrahim, 1994; Paddison et al., 1990). Finally, were included five articles that met criteria: Bertone-Johnson et al. (2014), Bunevicius et al. (2012); Fleischman, Bunevicius, Leserman, \& Girdler (2014), Girdler et al. (2007) and Girdler et al. (2003) (Figure 1).

\section{RESULTS}

\section{Quality assessment of the studies included}

The Grading of Recommendations Assessment, Development, and Evaluation (GRADE) criteria were used to evaluate the quality of the evidence. GRADE provides a guiding framework through the critical components of the quality assessment of the evidence that conforms the systematic review applied to a body of data and not to individual studies. Additionally, GRADE provides an approach to analysis and communication that encourages transparency and an explicit quantification of the judgments involved (Balshem et al., 2011). Then, the bias table was customized to take into account the following: 1. limitations related to the study design, 2. indirectness of evidence, 3 . inconsistency of results, 4. Imprecisión, and 5. other factors (i. e., publication bias, a dose-response gradient, and confounding variables). These five criteria were rated as low, unclear, and high risk of bias (Table 1). The results are presented below.

\section{Study design}

It is essential to mention that the inclusion criteria for the present work comprised of studies with a group of women who were not exposed to violence and yet presented MRMDs

\section{Table 1}

Risk of bias of the included articles based on GRADE criteria. Grey marks represent a low risk, white marks an unclear risk, and dark marks a high risk of bias.

Bertone-Johnson et al., 2014

Bunevicius et al., 2012

Fleischman et al., 2014

Girdler et al., 2003

Girdler et al., 2007

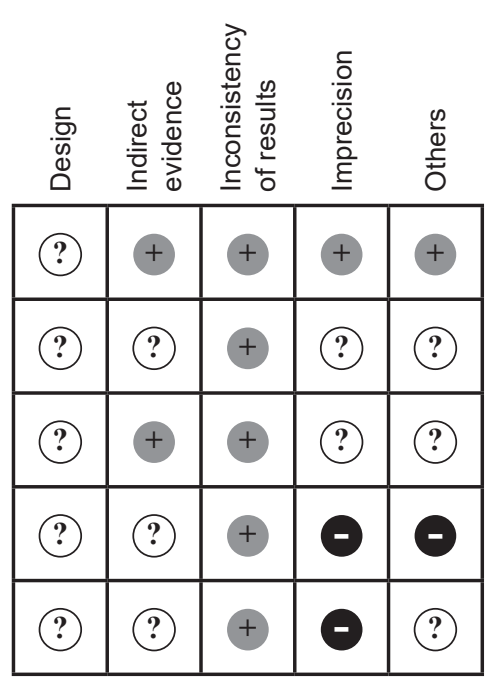


prospectively diagnosed. Therefore, all articles included herein have similar case-control designs, and they have been rated as an unclear risk, as with this type of study it cannot be established a causal relationship between variables.

\section{Indirectness of evidence}

The study by Bertone-Johnson et al. (2014) and Fleischman et al. (2014) included particular variables to direct their studies to a given population and to control for confounders concerning to the independent variable. For example, they included variables related to previous physical or mental diseases and phases of the menstrual cycle. The studies by Girdler et al. (2003) and (2007) included control variables but had fewer participants than the other studies. The participants included in Bunevicius et al. (2012) presented a wide standard deviation for age, and other measures, such as hypothalamus-pituitary-thyroid (HPT) axis activity at a single time point. Thus, some questions remain unclear, such as the effect of hormonal fluctuations on the luteal and follicular phases on the HPT measures.

\section{Inconsistency}

The studies by Girdler et al. (2003) and (2007), Bunevicius et al. (2012), Fleischman et al. (2014), and Bertone-Jonhson et al. (2014) reported similar findings, and are consistent with the conceptual evidence of MRMDs.

\section{Imprecision}

The study by Bertone-Jonhson et al. (2014) had the lowest confidence intervals (CI) because it had more participants than the other studies included. Bunevicius et al. (2012) did not report measures of association, but given the sample size, the CI for the meta-analysis was more precise than the studies by Girdler et al. (2003) and (2007). Nevertheless, the odds ratio (OR) could be overestimated given that exposure to sexual and/or physical violence was measured as a dichotomous variable. The same was observed in the study by Fleischman et al. (2014). Likewise, the sample sizes in Girdler et al. (2003) and (2007) were smaller; therefore the CI was larger than the other studies included.

\section{Others}

In the case of Bertone-Johnson et al. (2014), the authors made adjustments to reduce the impact of confounding variables on the results. Similarly, Fleischman et al. (2014) assessed that the potential confounding variables were controlled, and psychiatric disease to exclude women who presented comorbidity at the time of the study. The studies by Girdler et al. (2003) and (2007) and Bunevicius et al. (2012) pertained to the same workgroup and had similar findings. Even though these studies controlled some confounding variables, the authors acknowledged that the results might not have been sufficiently robust due to the modest sample sizes.

In short, as shown in Table 1, the major concern is the imprecision of the studies included in the present review. This imprecision is directly related to the sample sizes and the control of variables, especially those that play an important role as mediators or confounding variables. The risk of imprecision can also be observed in the forest plots, where the CI are high in some studies but low in others. However, it is important to note that the results were homogeneous and the tests for the effect of size were statistically significant. In addition, the total OR in the meta-analysis had tighter CI than the individual articles. Therefore, it is possible to draw a more robust statistically conclusion from the meta-analysis than from the evidence separately.

\section{Characteristics of articles included}

The results of the present study were obtained from a total of five articles that met the inclusion criteria. Four of the studies were conducted in the U.S. and one in the U.K. In short, were included a total of 1,076 women with a diagnosis of MRMDs and 2,094 control subjects, for a total of 3,170 participants.

\section{Diagnosis of MRMD}

The prospective diagnosis of MRMD was based on DSM-IV criteria (given the publication years of the articles, the DSM5 was not yet available). These included: a) classification of moderate-to-severe premenstrual symptoms (Girdler et al., 2003 and 2007); b) the occurrence of at least one physical symptom (Bertone-Johnson et al., 2014), or a total of five or more premenstrual symptoms (Girdler et al., 2003; 2007); c) at least one affective/emotional symptom; d) symptoms having a negative impact on the person's functionality (Bertone-Johnson et al., 2014; Girdler et al., 2003; 2007); e) symptoms beginning within 14 days of the start of menstruation (Bertone-Johnson et al., 2014) or at least three days prior to the menstrual period (Girdler et al., 2003; 2007); and f) the absence of symptoms in the follicular phase of the menstrual cycle (Bertone-Johnson et al., 2014; Girdler et al., 2003; 2007).

The studies by Bunevicius et al. (2012) and Fleischman et al. (2014) classified MRMDs when women met all of the following: 1 . at least $30 \%$ change in the severity of emotional symptoms during seven days before menses compared to the follicular phase; 2. rating of emotional symptoms as moderate, severe, or extreme on at least two of seven premenstrual days; 3 . remission of symptoms within three days of the onset of menses, followed by a symptom-free period ( $\geq$ six consecutive days) during the early to mid-follicular phase; and 4. criteria one through three are met at least during two menstrual cycles. 
In the studies by Girdler et al. (2003) and (2007), the authors utilized the Prospective Record of the Impact and Severity of Menstrual, which was completed daily for two menstrual cycles. Bunevicius et al. (2012) and Fleischman et al. (2014) used the Daily Record of Severity of Problems for two to three menstrual cycles. Bertone-Johnson et al. (2014) used a calendar of premenstrual experiences that contained 26 symptoms, including physical, behavioral, and affective domains. This was used throughout the menstrual cycle and included the impact on multiple areas of daily life, without specifying for how many cycles this instrument was applied.

To establish a control group without MRMD, the criteria were: a) asymptomatic women (Bertone-Johnson et al., 2014) or those with mild symptomatology (Bertone-Johnson et al., 2014; Girdler et al., 2003; 2007); b) only mild emotional premenstrual symptoms; c) moderate physical symptoms appearing before three days prior menstruation (Girdler et al., 2003; 2007), and d) symptoms that did not affect woman's functionality (Bertone-Johnson et al., 2014; Girdler et al., 2003; 2007). In the studies by Bunevicius et al. (2012) and Fleischman et al. (2014), women without MRMD met the following criteria: a) no more than minimal emotional symptoms occurring on fewer than two (Fleischman et al., 2014) or three (Bunevicius et al., 2012) days during the premenstrual week; b) less than $30 \%$ change in the severity of emotional symptoms from the luteal to the follicular phase; and c) meeting these criteria at least during two menstrual cycles.

\section{Age ranges for childhood and adolescence}

The studies included used different ranges to define childhood and adolescence. Girdler et al. (2003), Bunevicius et al. (2012) and Fleischman et al. (2014) define childhood as $\leq 13$ years old, and Girdler et al. (2007) define childhood abuse when events occur prior the 14 years old. Girdler et al. (2003) defined adolescence from 14 to 17 years old. In Girdler et al. (2007), events occurring between 14 and 19 years old were considered as adolescence abuse. Bertone-Johnson et al. (2014) considered childhood at $<11$ years old, and adolescence ranged from 11 to 17 years old.

\section{Indicators of physical abuse}

The indicators used by Girdler et al. (2003) to determine physical abuse were being hit or kicked, or the occurrence of life-threatening events. Girdler et al. (2007) defined physical abuse as life-threatening when being physically attacked (with or without a weapon) with the intention to kill or cause severe wounds, and defined blows, kicks, bites, and burns as other types of abuse. Fleischman et al. (2014) defined physical abuse as life-threatening when being attacked with the intent to kill or seriously injure, and other physical abuse as being beaten up, hit and burned. In Ber-
tone-Johnson et al. (2014), physical abuse was defined as shoving, grabbing, kicking, biting, blows to injure the body, asphyxia, burns, or physical attacks inflicted in some other manner. Bunevicius et al. (2012) did not include women with physical abuse in their study.

\section{Indicators of sexual abuse}

In Girdler et al. (2003), the indicators for sexual abuse were a) events involving forced sexual contact (with the hands, mouth, or with objects) or b) intercourse. In the case of Girdler et al. (2007), sexual abuse included a) sexual contact with the hands, mouth or objects, in which the subject touched the perpetrator with the hands, mouth, or objects, or b) vaginal or anal intercourse. For Bunevicius et al. (2012) and Fleischman et al. (2014), sexual abuse included a) touching the subject's breasts, pubic area, vagina, or anus with hands, mouth, or objects; b) making the subject touch the perpetrator's pubic area or anus with hands, mouth, or objects; or c) vaginal or anal intercourse. For Bertone-Johnson et al. (2014), abuse was classified as undesired, forced sexual contact that occurred more than once.

\section{Inquiry about Events of Sexual and/or Physical Abuse}

A validated and structured interview was utilized to inquiry for histories of sexual and/or physical abuse (Bunevicius et al., 2012; Fleischman et al., 2014; Girdler et al., 2003; 2007). In Bertone-Johnson et al. (2014), questions were taken from a modified version of the revised Conflict Tactics Scale Questionnaire (CTQ) for physical abuse, whereas for sexual abuse, the authors used some questions adapted from the Sexual Experiences Survey.

\section{Description of Results from Articles Included}

Bertone-Johnson et al. (2014) included 3,295 women. Authors reported significant differences between those who experienced physical abuse in childhood and those who did not $(95 \% \mathrm{CI}=3.1$; range $[2.3,4.2])$. For sexual abuse in childhood, forced sexual intercourse more than once was the sole category exhibiting significant differences $(\mathrm{OR}=1.6 ; 95 \%$ CI $[1,2.6])$. For sexual abuse in adolescence, being forced once to have sexual intercourse increased the probability of experiencing MRMD $(\mathrm{OR}=1.6 ; 95 \% \mathrm{CI}[1.1,2.2])$, as was the case for having been forced more than once $(\mathrm{OR}=2.1$; 95\% CI [1.3, 3.3]) (Bertone-Johnson et al., 2014). The study by Fleischman et al. (2014), which included 126 women, found that the prevalence of abuse was not different among MRMD women versus non-MRMD women. Bunevicius et al. (2012) included 109 women and reported frequencies of MRMD diagnosis and abuse history, finding no statistical association between these variables. Girdler et al. (2003) reported a frequency of 56 and Girdler et al. (2007) a frequency 
Table 2

Frequencies of women with Menstrually-Related Mood Disorders (MRMDs) and without MRMDs exposed, or not, to sexual and/or physical abuse in childhood and/or adolescence

\begin{tabular}{|c|c|c|c|c|c|c|c|c|c|c|c|c|c|c|}
\hline \multirow[b]{3}{*}{ Study } & \multirow[b]{3}{*}{ Age } & \multirow[b]{3}{*}{$n$} & \multicolumn{4}{|c|}{ Physical and sexual } & \multicolumn{4}{|c|}{ Only physical } & \multicolumn{4}{|c|}{ Only sexual } \\
\hline & & & \multicolumn{2}{|c|}{ MRMDs } & \multicolumn{2}{|c|}{ No MRMDs } & \multicolumn{2}{|c|}{ MRMDs } & \multicolumn{2}{|c|}{ No MRMDs } & \multicolumn{2}{|c|}{ MRMDs } & \multicolumn{2}{|c|}{ No MRMDs } \\
\hline & & & $A$ & $N A$ & $A$ & $N A$ & $A$ & $N A$ & $A$ & $N A$ & $A$ & $N A$ & $A$ & $N A$ \\
\hline Bertone-Johnson et al., 2014 & $34.1 \mathrm{SD}(4.1)$ & 3295 & 953 & 65 & 1989 & 288 & 628 & 323 & 1065 & 1157 & 376 & 637 & 656 & 1614 \\
\hline Fleischman et al., 2014 & $34.2 \mathrm{SD}(8.0)$ & 126 & 34 & 29 & 31 & 32 & 10 & 53 & 8 & 55 & 13 & 16 & 9 & 20 \\
\hline Bunevicius et al., 2012 & $34.4 \mathrm{SD}(7.4)$ & 109 & ---- & & ---- & --- & ---- & & ---- & --- & 23 & 34 & 18 & 34 \\
\hline Girdler et al., 2007 & $33.4 \mathrm{SD}(1.7)$ & 67 & 12 & 13 & 12 & 30 & 11 & 14 & 9 & 33 & 8 & 17 & 6 & 36 \\
\hline Girdler et al., 2003 & 33.7 SD (1.4) & 56 & 20 & 8 & 10 & 18 & 17 & 11 & 8 & 20 & 10 & 18 & 3 & 25 \\
\hline
\end{tabular}

Notes: Frequencies are reported according to the type of violence experienced in childhood and/or adolescence. $\mathrm{A}=\mathrm{Abused}$; NA $=\mathrm{Not}$ abused.

Source developed by authors based on data from Bertone-Johnson et al. (2014), Bunevicius et al. (2012), Fleischman et al. (2014), Girdler et al. (2003), and Girdler et al. (2007).

of 67; and both studies demonstrated a tendency towards a higher proportion of abused women having a diagnosis of severe MRMD in comparison to those who did not experience abuse.

Table 2 was constructed based on the frequencies reported in the articles. Bunevicius et al. (2012), Fleischman et al. (2014), and Girdler et al. (2003) and (2007) reported frequencies for physical and sexual abuse in childhood and adolescence for cases and controls, followed by physical abuse in childhood and adolescence, and lastly, sexual abuse in childhood and adolescence. Bertone-Johnson et al. (2014) dichotomized the abuse measurement, and the frequencies reported for cases and controls were based on the CTQ, with scores between 0 and 6 as "no abuse" and between 6 and 25 as "abuse." For physical abuse, the authors used the frequencies that the article reported as "only physical violence in childhood and adolescence," and for sexual abuse, they used the frequencies reported as "only sexual violence in childhood and adolescence."

\section{Meta-analysis results}

Review Manager (RevMan) software version 5.3. (2014) was used to generate forest plot graphs (Figures 2, 3, and 4) based on data from Table 2. All analyses were performed by fixed effects $\left(\mathrm{I}^{2}<50 \%\right)$. Figure 2 shows the effect of physical and/or sexual violence in childhood and/or adolescence on the development of MRMDs. As observed, the study by Bertone-Johnson et al. (2014) has the greatest weight in terms of the number of subjects included in their report, followed by Fleischman et al. (2014), Girdler et al. (2007), and lastly, Girdler et al. (2003). The fixed-effects analysis yielded an OR of 1.99 and a 95\% CI [1.58, 2.51]. This indicates that having been exposed to physical and/or sexual abuse in childhood and/or adolescence increases the risk of experiencing MRMDs in adulthood by 1.99 times in comparison with women who did not experience these types of violence (Figure 2).

When analyzed per types of violence separately, it was found that having experienced only physical abuse during childhood and/or adolescence increases two-fold the risk of developing MRMDs, in comparison with women who did not experience physical violence $(\mathrm{OR}=2.14 ; 95 \%$ CI [ 1.83 , 2.29]) (Figure 3 ). In addition, having only experienced sexual abuse (Figure 4) increases the risk of MRMDs by 1.49 compared to women who did not experience sexual violence $(\mathrm{OR}=1.49 ; 95 \%$ CI $[1.28,1.73])$.

\begin{tabular}{|c|c|c|c|c|c|c|c|c|}
\hline \multirow{3}{*}{$\frac{\text { Study or subgroup }}{\text { Bertone-Johnson et al., } 2014}$} & \multicolumn{2}{|c|}{ MRMD } & \multicolumn{2}{|c|}{ No MRMD } & \multirow[b]{2}{*}{ Weight } & Odds ratio & \multirow{2}{*}{\multicolumn{2}{|c|}{$\begin{array}{c}\text { Odds ratio } \\
\mathrm{M}-\mathrm{H} \text {, Fixed, } 95 \% \mathrm{Cl}\end{array}$}} \\
\hline & Events & Total & Events & Total & & M-H, Fixed, 95\% Cl & & \\
\hline & 953 & 1018 & 1989 & 2277 & $70.4 \%$ & $2.12[1.60,2.81]$ & & \\
\hline Bunevicius et al., 2012 & 23 & 57 & 18 & 52 & $10.1 \%$ & $1,28[.59,2.78]$ & & - \\
\hline Fleischman et al., 2014 & 34 & 63 & 31 & 63 & $12.8 \%$ & $1,21[.60,2.44]$ & & - \\
\hline Girdler et al., 2003 & 20 & 28 & 10 & 28 & $2.6 \%$ & $4.50[1.46,13.89]$ & & \\
\hline Girdler et al., 2007 & 12 & 25 & 12 & 42 & $4.2 \%$ & $2.31[.82,6.47]$ & & \\
\hline Total $(95 \% \mathrm{Cl})$ & & 1191 & & 2462 & $100.0 \%$ & $1.99[1.58,2.51]$ & & $\diamond$ \\
\hline Total events & 1042 & & 2060 & & & & & \\
\hline $\begin{array}{l}\text { Heterogeneity: } \mathrm{Chi}^{2}=5.48, \mathrm{df} \\
\text { Test for overall effect: } \mathrm{Z}=5.79\end{array}$ & $\begin{array}{l}4(\mathrm{P}=.24 \\
0<.0000\end{array}$ & $\begin{array}{l}\text { ); } I^{2}=27 \\
\text { 1) }\end{array}$ & & & & .01 & $\begin{array}{l}.1 \\
\text { No MRMD }\end{array}$ & ${ }_{\text {MRMD }}^{10}$ \\
\hline
\end{tabular}

Figure 2. Effect of physical and/or sexual abuse during infancy and/or adolescence on the development of Menstrually-Related Mood Disorders in adulthood. 


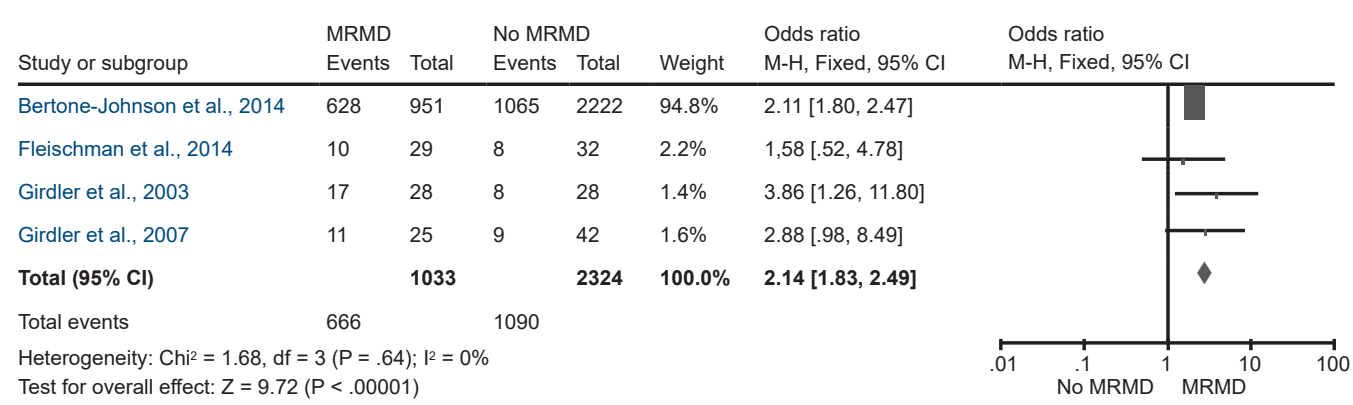

Figure 3. Effect of physical abuse in childhood and/or adolescence on the development of Menstrually-Related Mood Disorders in adulthood.

\section{DISCUSSION AND CONCLUSION}

The present review included case-control studies that treated physical or sexual violence in adolescence and/or childhood as an independent variable. Despite the modest number of reports included, the results showed that having been exposed to sexual or physical violence results in a nearly two-fold significant increase of the probability of developing MRMDs in adulthood.

These results are in agreement with several reports, despite the differences in the methodological approximation used, such as the instruments employed to measure premenstrual symptoms (DSM-IV vs. specific scales), the inclusion of other psychiatric pathologies (post-traumatic stress vs. MRMDs only), age when sexual and/or physical abuse occurred (childhood and adolescence vs. any other life stage), and the number of times that the abuse occurred, among others. For example, a study of PMS women (as a MRMD) found that over $80 \%$ were sexually or physically abused during childhood or adolescence and $65 \%$ of that population presented post-traumatic stress symptoms, and never received appropriate care (Golding et al., 2000). This report indicated that sexual or physical abuse during early developmental stages affects mental health in adulthood. In addition, a previous report analyzed the clinical history of women with sexual and physical abuse and its relation with PMS and demonstrated that women with a history of abuse exhibited more severe premenstrual symptoms in adulthood than those who were not abused (Koci \& Strickland, 2007). However, the authors only reported percentages and did not demonstrate a causal relation between abuse and MRMDs.

In the present meta-analysis it was observed that $87.48 \%$ of MRMDs women were sexually or physically abused during childhood and/or adolescence, indicating that these women may be a vulnerable population that requires professional health care. The high proportion of abused MRMDs women observed in the present work contrasts with other studies in which the prevalence of both, abuse and MRMDs, was either lower (Kovac et al., 2003) or a relation between the two events was not found (Segebladh et al., 2011). In this regard, Kovac et al. (2003) found no association between MRMDs and sexual or physical abuse. Likewise, only $4 \%$ of the population exposed to these types of violence was more affected by psychiatric diseases, psychological stress, somatic symptoms, and poor health in patients abused only in adulthood. Similarly, Segebladh et al. (2011) reported no relationship between the number of abuses and the development of severe MRMD in comparison with abused women without MRMDs. Interestingly, the studies that found no relation between MRMD and abuse

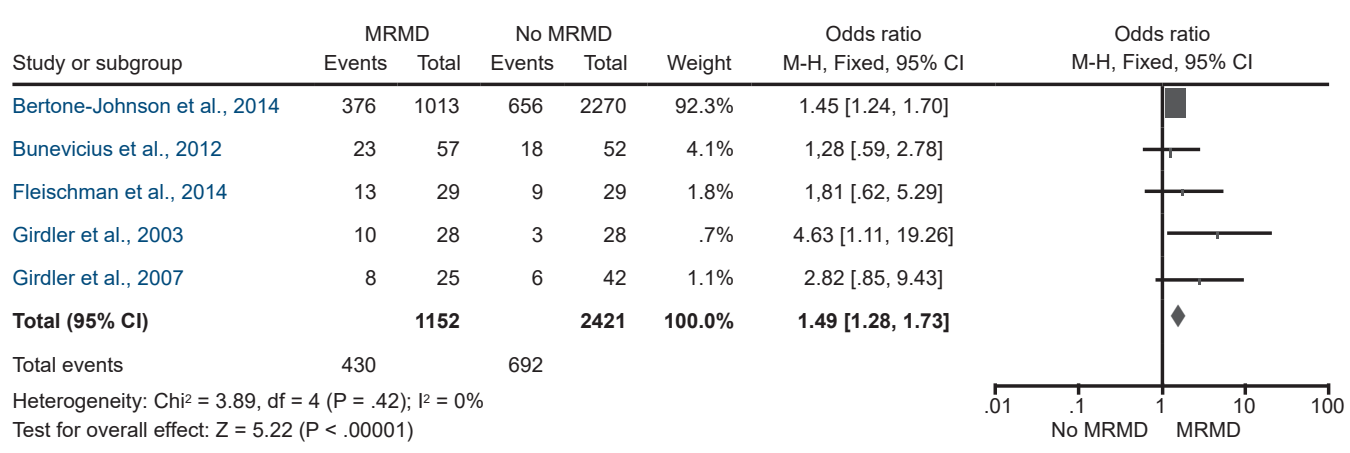

Figure 4. Effect of sexual abuse in infancy and/or adolescence on the development of Menstrually-Related Mood Disorders in adulthood. 
included participants who were exposed to physical or sexual abuse only in adulthood. Therefore, the discrepancies observed between our results and the studies from Kovac et al. (2003) and Segebladh et al. (2011) could be related to the age when the abuse occurred, as the present review included studies in women who experienced abuse during childhood and/or adolescence. Thus, the perception of the abuse may be dissimilar depending of age and it may contribute to stress management differently. In fact, Segebladh et al. (2011) proposed that treating abused individuals at early stages could contribute to decreasing the perception of MRMDs symptoms. On the other hand, these studies used different instruments to diagnose MRMDs, which may also contribute to explain the discrepancies observed.

An additional factor that the meta-analysis did not include due to methodological differences was an association between sexual and/or physical abuse and impairments in the stress response system in women with MRMDs. A previous study reported that $50 \%$ of abused women had severe MRMD and presented a blunted stress response of the HPA axis, as were observed lower cortisol and lower heart rates, but higher noradrenaline, when compared to control subjects. Furthermore, abused women with MRMDs reported having higher life stress than the control women (Girdler et al., 1998). Later studies provided more evidence that sexual and/or physical abuse at early life stages impairs the stress response of the HPA axis in women with severe MRMD (Girdler et al. 2003; 2007). However, a limitation of these findings is that the reports belong to the same workgroup; in this regard, more research is encouraged to potentially assert whether this phenomenon is presented in the same manner among women with MRMDs. In fact, a previous study proposed that sexual or physical abuse are important factors for developing stress, and interestingly women with a high perception of psychological and physical stress have more severe premenstrual symptoms (Lustyk, Widman \& Becker, 2008). Taking the evidences together, it is feasible to state that women exposed to physical and/or sexual abuse have a higher perception of stress that could lead, in turn, to the HPA axis dysregulation along with the lack of inhibition of the stress response, thereby increasing the severity of premenstrual symptoms, a proposal that is in line with Girdler et al. (1998).

An important limitation of the present work is that four of the studies included in the meta-analysis corresponded to the same workgroup (Bunevicius et al., 2012; Fleischman et al., 2014; Girdler et al., 2003; 2007). Although the samples were different, the results obtained may not be exempt from risk of bias due to the selection criteria utilized. In this case, the sample selection was based on the DSM-IV criteria for PMDD as severe MRMD, and in all cases, the control groups comprised asymptomatic women or with mild physical and psychological premenstrual symptoms (Bunevicius et al., 2012; Fleischman et al., 2014; Girdler et al.,
2003; 2007). Furthermore, in these studies, the probability for developing MRMD was calculated from the sample, as they only reported frequencies. Finally, it was observed a wide range of ages among women participants in the studies included, thus the perception of premenstrual symptomatology could vary, and thereby modify the risk value.

Overall, our findings suggest that a woman who experienced physical and/or sexual abuse during childhood and/or adolescence has nearly a two-fold greater probability for developing MRMDs in adulthood. However, controlled studies are imperative to gain a better understanding of the development of MRMDs, and importantly, to create timely care strategies to prevent psychiatric disorders that impair women's health. Even more so, it has been reported that experiencing MRMDs increases the risk of postpartum depression (MacKenzie \& Maguire, 2014). This, in turn, contributes to the development of depression and/or anxiety in the perimenopause (Studd \& Nappi, 2012) compromising the welfare of affected women across their adult lifespan.

\section{Funding}

I-P D, F-C K received funding from "Proyecto igualdad entre hombres y mujeres," Instituto Nacional de las Mujeres.

\section{Conflict of interest}

The authors declare they have no conflicts of interest.

\section{Acknowledgements}

The authors thank Dr. Rodolfo Rivas Ruiz and Dr. Ruth Alcalá for their invaluable support and comments to the manuscript and Ellen Weiss for the English revision.

\section{REFERENCES}

American Psychiatric Association [APA]. (2000). Diagnostic and Statistical Manual of Mental Disorders, (4th ed. Text revision). Washington, D.C.: American Psychiatric Publishing.

American Psychiatric Association [APA]. (2013). Diagnostic and Statistical Manual of Mental Disorders (DSM-5 ${ }^{\circledR}$ ). Arlington, VA.: American Psychiatric Publishing.

Balshem, H., Helfand, M., Schünemann, H. J., Oxman, A. D., Kunz, R., Brozek, J., ... Guyatt, G. H. (2011). GRADE guidelines: 3. Rating the quality of evidence. Journal of Clinical Epidemiology, 64(4), 401-406. doi: 10.1016/j. jclinepi.2010.07.015

Bertone-Johnson, E. R., Whitcomb, B, W., Missmer, S. A., Manson, J. E., Hankinson, S. E., \& Rich-Edwards, J. W. (2014). Early life emotional, physical and sexual abuse and the development of premenstrual syndrome: a longitudinal study. Journal of Women's Health, 23(9), 729-739. doi: 10.1089/jwh.2013.4674

Bunevicius, A., Leserman, J., \& Girdler, S. S. (2012). Hypothalamic-pituitary-thyroid axis function in women with a menstrually related mood disorder: association with histories of sexual abuse. Psychosomatic Medicine, 74(8), 810-816. doi: 10.1097/PSY.0b013e31826c3397

Bunevicius, A., Rubinow, D. R., Calhoun, A., Leserman, J., Richardson, E., Rozanski, K., \& Girdler, S. S. (2013). The association of migraine with menstrually related mood disorders and childhood sexual abuse. Journal of Women's Health, 22(10), 871-876. doi: 10.1089/jwh.2013.4279

Cochrane Denmark. (2014). Review Manager (RevMan) version 5.3. Copenhagen: The Nordic Cochrane Centre, The Cochrane Collaboration. 
Crowley, S. K., Pedersen, C. A., Leserman, J., \& Girdler, S. S. (2015). The influence of early life sexual abuse on oxytocin concentrations and premenstrual symptomatology in women with a menstrually related mood disorder. Biological Psychology, 109, 1-9. doi: 10.1016/j.biopsycho.2015.04.003

Ersoy, O. Ç., \& Yildiz, H. (2011). Reproductive health problems and depression levels of women living in sanctuary houses as a result of husband violence. Health Care for Women International, 32(9), 795-810. doi: 10.1080/07399332.2011.565528

Fleischman, D. S., Bunevicius, A., Leserman, J., \& Girdler, S. S. (2014). Menstrually related mood disorders and a history of abuse: Moderators of pain sensitivity. Health Psychology, 33(2), 147-154. doi: 10.1037/a0031900

Girdler, S. S., Leserman, J., Bunevicius, R., Klatzkin, R., Pedersen, C. A., \& Light, K. C. (2007). Persistent alterations in biological profiles in women with abuse histories: influence of premenstrual dysphoric disorder. Health Psychology, 26(2), 201-213. doi: 10.1037/0278-6133.26.2.201

Girdler, S. S., Pedersen, C. A., Straneva, P. A., Leserman, J., Stanwyck, C. L., Benjamin, S., \& Light, K. C. (1998). Dysregulation of cardiovascular and neuroendocrine responses to stress in premenstrual dysphoric disorder. Psychiatry Research, 81(2), 163-178. doi: 10.1016/S0165-1781(98)00074-2

Girdler, S. S., Sherwood, A., Hinderliter, A. L., Leserman, J., Costello, N. L., Straneva, P. A., ... Light, K. C. (2003). Biological correlates of abuse in women with premenstrual dysphoric disorder and healthy controls. Psychosomatic Medicine, 65(5), 849-856. doi: 10.1097/01.PSY.0000088593.38201.CD

Girdler, S. S., Thompson, K. S., Light, K. C., Leserman, J., Pedersen, C. A., \& Pranger Jr, A. J. (2004). Historical sexual abuse and current thyroid axis profiles in women with premenstrual dysphoric disorder. Psychosomatic Medicine, 66(3), 403-410. doi: 10.1097/01.psy.0000127690.38525.ab

Golding, J. M., Taylor, D. L., Menard, L., \& King, M. J. (2000). Prevalence of sexual abuse history in a sample of women seeking treatment for premenstrual syndrome. Journal of Psychosomatic Obstetrics \& Gynecology, 21(2), 69-80. doi: 10.3109/01674820009075612

Hantsoo, L., \& Epperson, C. N. (2015). Premenstrual dysphoric disorder: Epidemiology and treatment. Current Psychiatry Reports, 17(11), 87. doi: 10.1007/s11920-015-0628-3

Howard, R. C., Mason, P. A., \& Ebrahim, T. (1994). Impulsivity, mood and the contingent negative variation in women with and without premenstrual changes in impulsive behaviour. Personality and Individual Differences, 16(4), 605-616. doi: 10.1016/0191-8869(94)90188-0

Klatzkin, R. R., Morrow, A. L., Light, K. C., Pedersen, C. A., \& Girdler, S. S. (2006). Histories of depression, allopregnanolone responses to stress, and premenstrual symptoms in women. Biological Psychology, 7l(1), 2-11. doi: 10.1016/j. biopsycho.2005.02.007

Koci, A., \& Strickland, O. (2007). Relationship of adolescent physical and sexual abuse to perimenstrual symptoms (PMS) in adulthood. Issues in Mental Health Nursing, 28(1), 75-87. doi: 10.1080/01612840600996281

Kovac, S. H., Klapow, J. C., Kroenke, K., Spitzer, R. L., \& Williams, J. B. (2003). Differing symptoms of abused versus nonabused women in obstetricgynecology settings. American Journal of Obstetrics and Gynecology, 188(3), 707-713. doi: $10.1067 / \mathrm{mob} .2003 .193$

Liberati, A., Altman, D. G., Tetzlaff, J., Mulrow, C., Gøtzsche, P. C., Ioannidis, J. P., ... Moher, D. (2009). The PRISMA statement for reporting systematic reviews and meta-analyses of studies that evaluate health care interventions: Explanation and elaboration. PLoS Medicine, 6(7), e1000100. doi: 10.1371/ journal.pmed.1000100

Lustyk, M. K. B., Widman, L., \& Becker, L. de L. (2008). Abuse history and premenstrual symptomatology: Assessing the mediating role of perceived stress. Women \& Health, 46(4), 61-80. doi: 10.1300/J013v46n04_04
MacKenzie, G., \& Maguire, J. (2014). The role of ovarian hormone-derive neurosteroids on the regulation of GABAA receptors in affective disorders. Psychopharmacology, 231(17), 3333-3342. doi: 10.1007/s00213-013-3423

McEwen, B. S. (1998). Protective and damaging effects of stress mediators. New England Journal of Medicine, 338(3), 171-179. doi: 10.1056/ NEJM199801153380307

McEwen, B. S., Eiland, L., Hunter, R. G., \& Miller, M. M. (2012). Stress and anxiety: Structural plasticity and epigenetic regulation as a consequence of stress. Neuropharmacology, 62(1), 3-12. doi: 10.1016/j.neuropharm.2011.07.014

Paddison, P. L., Gise, L. H., Lebovits, A., Strain, J. J., Cirasole, D. M., \& Levine, J. P. (1990). Sexual abuse and premenstrual syndrome: Comparison between a lower and higher socioeconomic group. Psychosomatics, 31(3), 265-272. doi: 10.1016/S0033-3182(90)72162-7

Pearlstein, T., \& Steiner, M. (2012). Premenstrual dysphoric disorder: Burden of illness and treatment update. Focus, 10(1), 90-101. doi: 10.1176/appi. focus. 10.1 .90

Roca, C. A., Schmidt, P. J., Altemus, M., Deuster, P., Danaceau, M. A., Putnam, K., \& Rubinow, D. R. (2003). Differential menstrual cycle regulation of hypothalamic-pituitary-adrenal axis in women with premenstrual syndrome and controls. Journal of Clinical Endocrinology \& Metabolism, 88(7), 3057-3063. doi: $10.1210 /$ jc. $2002-021570$

Ross, L. E., \& Steiner, M. (2003). A biopsychosocial approach to premenstrual dysphoric disorder. Psychiatric Clinics of North America, 26(3), 529-546. doi: 10.1016/S0193-953X(03)00035-2

Schalinski. I., Elbert, T., Steudte-Schmiedgen, S., \& Kirschbaum, C. (2015). The cortisol paradox of trauma-related disorders: lower phasic responses but higher tonic levels of cortisol are associated with sexual abuse in childhood. PLoS One, 10(8), e0136921. doi: 10.1371/journal.pone.0136921

Segebladh, B., Bannbers, E., Kask, K., Nyberg, S., Bixo, M., Heimer, G., \& Sundström-Poromaa, I. (2011). Prevalence of violence exposure in women with premenstrual dysphoric disorder in comparison with other gynecological patients and asymptomatic controls. Acta Obstetricia et Gynecologica Scandinavica, 90(7), 746-752. doi: 10.1111/j.1600-0412.2011.01151

Sousa-Rodrigues, C. F. de, Gusmão, L. C. B. de, Pereira, G. O., Bárbara, G. H. S., Bezerra Júnior, D. L., \& Jesus, S. R. R. de. (2006). Prevalence and severity of premenstrual syndrome symptoms in arrested women condemned by violent crimes. Jornal Brasileiro de Psiquiatria, 55(1), 58-61. doi: 10.1590/S004720852006000100008

Soyda Akyol, E., Karakaya Arısoy, E. Ö., \& Çayköylü, A. (2013). Anger in women with premenstrual dysphoric disorder: Its relations with premenstrual dysphoric disorder and sociodemographic and clinical variables. Comprehensive Psychiatry, 54(7), 850-855. doi: 10.1016/j.comppsych.2013.03.013

Spitzer, R. L., Severino, S. K, Williams, J. B, \& Parry, B. L., (1989). Late luteal phase dysphoric disorder and DSM-III-R. American Journal of Psychiatry, 146(7), 892-897. doi: 10.1176/ajp.146.7.892

Studd, J., \& Nappi, R. E. (2012). Reproductive depression. Gynecological Endocrinology, 28(sup1), 42-45. doi: 10.3109/09513590.2012.651932

Trickett, P. K., Noll, J. G., Susman, E. J., Shenk, C. E., \& Putnam, F. W. (2010). Attenuation of cortisol across development for victims of sexual abuse. Development and Psychopathology, 22(1), 165-175. doi: 10.1017/ S0954579409990332

Wittchen, H.-U., Perkonigg, A., \& Pfister, H. (2003). Trauma and PTSD - An overlooked pathogenic pathway for Premenstrual Dysphoric Disorder? Archives of Women's Mental Health, 6(4), 293-297. doi:10.1007/s00737-003-0028-2

Yonkers, K. A., O’Brien, P. S., \& Eriksson, E. (2008). Premenstrual syndrome. The Lancet, 371(9619), 1200-1210. doi: 10.1016/S0140-6736(08)60527-9 